\title{
FORMAS DE NARRACIÓN ÍNTIMA Y EL ESTATUTO DISCURSIVO EN LAS SOMBRAS QUE PEREGUIMOS
}

\author{
Jorge Chen Sham \\ Universidad de Costa Rica
}

Con la novela Las sombras que perseguimos de Rima de Vallbona, la narrativa costarricense se introduce con vigor hacia un campo muy poco explorado por nuestra literatura, pues destaca y enarbola su estatuto ficcional mediante sus condiciones de producción; por esta razón se refiere a sí misma como proceso de escritura-lectura que remite menos a la realidad y más a su especificiadad como lenguaje. Esta conciencia literaria pone de relieve las innovaciones y las rupturas con las que el texto descolla en el contexto costarricense: los desplazamientos y transformaciones del tiempo y del espacio, el modo y los registros narrativos, los intertextos múltiples e imprevistos, el rompimiento con el orden tradicional del relato, la tematización que realiza sobre el acto de novelar. En una palabra, al mostrar una nueva concepción teórica de lo que es la creación literaria pone en escena no solo su diferencia epistemológica, sino también su conciencia metaficcional.

Desde este punto de vista, es necesario abordar las condiciones internas de enunciación que el texto mismo ofrece para lograr una descodificación aceptable por parte de una comunidad hermeneútica. Lo más interesante es que estas condiciones se instituyen en el acto mismo de escritura de la cual la situación comunicativa del texto es su centro neurálgico, por lo cual la: "identidad del narrador, el grado y la forma en que se indique en el texto, y las indicaciones que se impliquen, confieren su carácter específico" (Bal 1985: 126). Es decir, la forma y el modo en que se realice la comunicación, en el acto de escritura, determina los alcances y la posible descodificación del texto.

En lo que se refiere a Las sombras que perseguimos, su circuito comunicativo es de índole intimista, desde el momento en que estamos ante una situación narrativa autobiográfica, caracterizada por esa imbricación y paradójica diferencia entre el sujeto del enunciado y el sujeto de la enunciación, pues como señala Jean Starobinski, el yo actual aborda los acontecimientos del pasado desde su situación presente y a partir de la conciencia que posee del proceso. De esta manera, la escritura autobiográfica está mediatizada por su presente en tanto sirve de punto de discriminación a la hora de narrar; dice lo siguiente:

El valor autorreferencial del estilo remite pues al momento de la escritura, al yo actual. Esta autorreferencia actual puede resultar un obstáculo para la captación fiel y la reproducción exacta de los acontecimientos pasados (...) A decir verdad, 
sólo se puede evocar el pasado a partir del presente: la verdad de los días pasados existe sólo para la conciencia que, al recoger su imagen en la actualidad, no puede dejar de imponerle su forma y su estilo (Starobinski 1974: 66-67).

Como subraya Starobinski, es la conciencia del presente lo que va moldeando la percepción del pasado, de modo que el relato se transforma en una autointerpretación de su proceso, de un conocimiento recapitulador. Razón por la cual toda escritura autobiográfica obliga al sujeto a recorrer su vida oblicuamente para justificar lo que se es y lo que se ha llegado a ser.

No cabe duda de que, en relación con el texto en estudio, la escritura autobiográfica cubre el espectro comunicacional y la cobertura discursiva más amplios, pues nos encontramos, ya sea con los papeles que ha dejado Cristina Osorio de Villalobos para que sirvan de testamento y justificación de su decisión final de acabar tal vez con su vida; ya sea con la novela de ficción de un malogrado e incipiente novelista, Pedro Almirante, cuyo relato es leído e interpretado, en la sintagmática, como si fuera una novela autobiográfica con elementos diarísticos. En este sentido, ambos sujetos van reconstruyendo sus experiencias capitales y formadoras, sus anhelos y temores, porque los narradores se sitúan en la apremiante necesidad de comprenderse a sí mismos, de manera que sus relatos constituyen una tentativa nunca acabada y perentoria de quien explora su biografía personal con el fin de moldear una versión más auténtica del yo (Navajas 1993: 122-126).

Y este proceso de autoconocimiento queda así caracterizado, y no es mera coincidencia ni recurso inocente, en el inicio del relato de Pedro Almirante: “¿Quién soy yo? ¡Preguntas! Sólo preguntas y no logro responderme ninguna. ¿Qué hago aquí en el mundo? ¿Adónde voy?” (Vallbona 1986: 17). De manera que el sujeto autobiográfico enfoca la escritura a partir de un punto necesario y límite que, aunque esté ocurriendo todavía, se concibe como el elemento que desencadena el proceso recapitulador: Pedro Almirante hace un balance de una vida de fracasos y de mediocridades, a pesar de los ideales y de aquellas lecturas y personas que hayan podido influir en su formación y que auguraban un porvenir aceptable. En este sentido, se trata de un escritor frustrado que lo único que puede escribir son unas cuantas anécdotas y algunas cavilaciones acerca de su existencia, sin lograr y hasta diferir la redacción de su gran obra.

En el caso del relato de Cristina, las mismas observaciones son pertinentes. Su escritura no es mera transcripción de unos hechos pensados previamente; es una experiencia activa con la que el sujeto pretende situarse en un punto de vista más genuino y auténtico, por lo cual su narración se perfila a partir de una oposición o diferencia frente a convenciones morales y éticas a las que la sociedad sujeta a las mujeres y esto únicamente lo empieza a descubrir al término del proceso. Se trata de una anagnórisis que ensaya liberar al sujeto de su alienación y desde este punto de vista, es significativo que sean las últimas palabras con las que Cristina clausura su relato las que permitan dar cuenta de su conciencia recobrada: “¡Si fuera la muerte! ¡Pero si apenas estoy naciendo ahora mismo!"' (Vallbona 1986:183).

Ahora bien, ¿qué parte de sus vivencias exploran ambos sujetos? ¿Para qué lo hacen? Claro está, la respuesta no se encuentra tanto en lo que ambos narran y comentan, sino en la interpretación que realizan del proceso mismo y que solo es posible captar en la tensión misma de toda autobiografía. Por esa razón, en ambos sujetos la escritura autobiográfica se rebela como un agente de liberación que desencadena, por consiguiente, una reconstrucción de las vivencias. El redescubrimiento de sí mismo significa, en el caso de Pedro Almirante, comprender el sometimiento y 
la anulación de un hombre que no supo luchar porque no tuvo las suficientes agallas y fuerzas para forjarse un destino a sus ambiciones; o en el caso de Cristina, de una mujer que, obligada por la sociedad a reprimir la posibilidad de ser, descubre, en la violencia verbal y psicológica de su marido, la necesidad de buscar su propia realización.

Vistas así las cosas, parece extraño afirmar la existencia de una liberación cuando sabemos que ambos sujetos son anulados, pues Pedro muere en un accidente que había previsto concientemente, según la carta que deja como nota suicida y Cristina, aunque presienta que su marido desea acabar con su vida, no puede hacer nada para detenerlo, de manera que se abandona a su suerte. Entonces, ¿dónde encontrar la liberación de ambos? Esta pasa y solamente es percibida gracias a la escritura y a la utilización de la memoria como recurso terapeútico, sin la cual es imposible desencadenar el proceso autobiográfico, pues de esta liberación surge la indagación emancipatoria; al respecto agrega Marcuse: "El pasado redescubierto proporciona niveles críticos que han sido convertidos en tabús por el presente” (1968:31-32).

Por otra parte, conviene agregar que la escritura autobiográfica es, por naturaleza, de carácter intimista y se realiza en un circuito de comunicación que posee este mismo rasgo, de manera que cobra tal relieve la expresividad del sujeto. Como nos recuerda José Luis Aranguren: "La intimidad es, ante todo, 'vida interior' (...) relación intrapersonal o intradiálogo, reflexión sobre los propios sentimentos, conciencia, tanto en el sentido gnoseológico, como en el de conciencia moral; y también autonarración y autointerpretación, contarse a sí mismo la propia vida y subjetividad, sintiéndolas como tales" (1989:20). No quisiera detenerme en los rasgos que subraya Aranguren y que son consustanciales al proceso autobigráfico, me interesa destacar solamente que la intimidad puede ser transgredida por el propio sujeto o por los otros. En este sentido, es necesario establecer una diferenciación de ese espacio o ámbito en el que los sujetos viven la socialidad, pues "Las actuaciones (...) son públicas, privadas o íntimas no en sí mismas, sino según el espacio en que se desenvuelven” (Castilla del Pino 1989a:26). Así, dado el hecho de que el sujeto es el único que puede mirar y observar su interioridad, la escritura autobiográfica corresponde a una actuación situada en este espacio de lo íntimo que, en el caso de ambos narradores, no se preserva sino que se transgrede desde el momento en que Benito entrega la "libreta" de los apuntes biográficos de Pedro Almirante para que los lea y los interprete el lector virtual (Vallbona 1986:14), interceptando el proceso de comunicación, pues el manuscrito está dirigido a los jueces de un concurso literario, con la clara indicación de que el texto es una novela: "Adjunta les envío mi entrañable novela, para que juzguen. Llego ante ustedes desconocido como todo autor bisoño, pero con una ansia inextinguible de permanecer" (Vallbona 1986:160).

Lo mismo ocurre con los escritos de Cristina; la transgresión radica en el hecho de que, como dice la carta que los acompaña, Josefa de Osorio, su hermana, descubra el manuscrito, cuando nos percatamos de que Cristina los ha preservado de cualquier ojo exterior, desde el momento en que los ha mantenido en secreto y ocultos debajo de su cama (Vallbona 1986: 165). Sin embargo, existe una doble transgresión; la primera corresponde al uso que Josefa pretende darle a los escritos de Cristina, los quiere como prueba documental de su asesinato y para ello se los dirige al abogado que llevará, lo más seguro, la causa; la segunda corresponde a la indiscreción cometida por Benito, pues está revelando algo que debería mantener en la más estricta confidencialidad, en el ámbito de lo privado. 
Estas transgresiones en la escritura autobiográfica producen, a su vez, transformaciones en la situación comunicativa de ambos relatos, a causa de ese desfase entre lo íntimo y su ulterior allanamiento en la persona de Benito. Obsérvese, en este sentido, cómo Benito, al dirigirse a su interlocutor y destinatario privilegiado de su discurso desde que le solicita una interpretación de ambos relatos, permite descodificar de otra manera su significado y su alcance; lo que escribe Pedro se convierte en una nota suicida y el relato de Cristina en una prueba incriminatoria. Al mismo tiempo, la transgresión produce una oscilación mucho más significativa aún, gracias a los criterios de autentificación que emergen en Las sombras que perseguimos, pues el texto problematiza, en sus condiciones de producción, las fronteras que separan la ficción de la realidad; Benito no solo discute, en lo referido al relato de Cristina que parece incriminarlo, cómo su fantasía y mentiras pueden destruir su reputación y conducirlo a la cárcel: "También literatura, fantasía, todo para hundir a un carajo honrado, trabajador y que fue un marido modelo" (Vallbona 1986:164), sino también cómo el relato de Pedro cambia su estatuto discursivo, al considerarlo en primer lugar historia auténtica (Vallbona 1986:15) y luego producto de la ficción y sin valor (Vallbona 1986: 163).

De manera que, internamente, el estatuto auténtico de la escritura autobiográfica se encuentra cuestionado por un personaje que arroga sus derechos sobre la interpretación-lectura a la que asistimos los lectores de Las sombras que perseguimos, en una estrategia enunciativa que justificaría la culpa y los temores que pesan sobre Benito, cruel explotador, y las contradicciones de su interpretación se comprenderían como una excusatio y una captatio benevolentiae nunca reveladas, en el sentido de que las oscilaciones hermenéuticas se podrían comprender como una defensa, es decir, como un alegato en favor de su inocencia. Así, la insistencia por convencer a su lector-auditor, en un plano superficial, parece responder a una situación de confidencia (relación de confianza) "que se genera por la necesidad que alguien tiene de contar algo a otro, algo a lo cual sólo él ha tenido acceso, bien porque pertenece a su intimidad, bien porque, siendo de otro, únicamente él ha tenido conocimiento de ello" (Castilla del Pino 1986b: 101); sin embargo, en el plano de las inferencias, mostraría una preocupación, transformada ahora en una obsesión porque se oculta algo o se quiere escamotear la responsabilidad.

$\mathrm{El}$ aparente acto de confidencia se invalida tanto con las vacilaciones con las que Benito desea impregnar el valor de los textos autobiográficos en cuestión (cuestionamiento de la autenticidad de la escritura autobiográfica), como con la excesiva premura en dar e imponer su propia interpretación de los textos (afirmación de su carácter ficcional identificado aquí como falso, mentiroso y de poco valor). Inferencias obligan y se desprende de lo anterior que el pseudo-acto de confidencia realizado por Benito es una excusa, porque ha mentido y nos está engañando "la no explicitación, en la doblez del acto, la encubierta inconexión entre lo que (dice) y lo que, de hecho, pretend(e) conseguir sin que el otro lo aperciba, puesto que se trata de engañarle" (Campos 1989:33).

Por esta razón, su pseudo-acto es una compleja manipulación discursiva, que pone de manifiesto, como lo recuerda Campos, el abuso de lenguaje que arrastra todo acto de mentira para no ser descubierto; son las llamadas razones o excusas "que justifiquen la improcedencia o el abuso del acto" (1989:34). En el caso de Benito, se protege ya que está en peligro de ser acusado y califica los textos autobiográficos de carácter auténtico de ser falsos y ficcionales, de manera que establece no solo la no correspondencia entre escritura-realidad, sino también una gran distancia entre la palabra simulada y engañosa de Cristina y la suya auténtica y verdadera. 
Pero, ¿cómo aceptar la posición de Benito, cuando su versión se contradice con la contigüidad del texto de Pedro Almirante? Recordemos que, en un principio, Benito está asombrado de las coincidencias entre la Cristina de Pedro Almirante y la suya, como si la historia de aquélla calzara perfectamente con la biografía personal de su esposa. No duda en su carácter auténtico, lo cual se refuerza, desde un punto de vista interno, con los numerosos recortes periodísticos y cartas que ofrece Pedro Almirante sobre la historia de su amigo y que se incluyen en un afán de instaurar la veracidad de su historia, la de Pedro Almirante. Sin embargo, el mismo Pedro Almirante pone en duda el estatuto discursivo de su producción al presentar el relato de su vida, en la carta dirigida al jurado del concurso literario, como si fuera una novela también. Es otro deslizamiento que produce ambigüedad discursiva. Está también la carta de la hermana de Cristina, Josefa de Osorio, la cual ofrece Benito a su lector-auditor como prueba del proceso de calumnia y difamación que organiza su cuñada; carta que lo compromete porque, en ella, Josefa explica las razones para hacer público las memorias de Cristina y las conclusiones a las que aquélla ha llegado luego de leer el texto de su hermana: Benito ha abusado de Cristina y la ha conducido a la muerte.

Por lo tanto, todo parece indicar que el lector-auditor debe y está en la obligación de resolver y determinar el estatuto discursivo de la escritura autobiográfica y la instancia acreedora de la verdad. Siguiendo de esta manera una larga tradición que inaugura el perspectivismo cervantino, las contradicciones de interpretación por parte de Benito no terminan por incriminarlo; todo lo contrario desencadena una ambigüedad hermeneútica que el lector debe zanjar: ¿es Benito una víctima o un victimario?, y ¿son pura ficción o verdad auténtica lo que escriben Pedro y Cristina?

\section{Bibliografia}

Aranguren, José Luis. 1989. "El ámbito de la intimidad”. En : Castilla del Pino (ed), 17-24.

Bal, Mieke. 1985. Teoría de la narrativa (una introducción a la narratología) Madrid: Ediciones Cátedra.

Campos, Victoria. 1989. "La mentira como presupuesto". En: Castilla del Pino (comp.) 29-41

Castilla del Pino, Carlos. 1989a. "Público, privado, íntimo". En: Castilla del Pino (ed.), 25-31

Castilla del Pino, Carlos. 1989b. "Confidencialidad”. En: Castilla del Pino (ed), 97-118.

Castilla del Pino, Carlos (ed.). 1989. De la intimidad. Barcelona: Editorial Crítica.

Castillo del Pino, Carlos (comp.). 1989. El discurso de la mentira. Madrid: Alianza Editorial.

Marcuse, Helbert. 1968. Eros y civilización. Barcelona: Editorial Seix Barral. 
Navajas, Gonzálo. 1993. "Una estética para después del posmodernismo: la nostalgia asertiva y la reciente novela española”. Revista de Occidente (143): 105-130.

Starobinski, Jean. La relación crítica (Psicoanálisis y literatura). Madrid: Ediciones Taurus.

Vallbona, Rima de. 1986. Las sombras que perseguimos. San José: Editorial Costa Rica. 